DOI: 10.20472/IAC.2017.034.001

\author{
LEAH ACHDUT \\ The Ruppin academic Center, Israel
}

\title{
WEALTH INEQUALITY AND INCOME INEQUALITY
}

\begin{abstract}
:
Wealth inequality and the contribution of wealth to households' well-being have received an increasing attention during the last years. This study examines the patterns of wealth inequality and the correspondence between the distributions of income and wealth. It takes advantage of a unique and multidisciplinary longitudinal survey on people aged 50 and older in Israel, conducted as part of the SHARE project (Survey of Health, Aging and Retirement in Europe). SHARE includes detailed information on disposable income and on the value of the various components of real assets, financial assets and debts. All this information allows us to construct a broad net worth measure on the household level. Based on the third wave of SHARE-Israel, the distributions of wealth and of income are examined by several measures: the mean to median ratio; the value of wealth at different percentile points of the distribution and percentile ratios; inequality measures - Gini coefficient and the General Entropy measure $(\alpha=2)$; and transition matrices based on the quintile distributions of income and net worth.

We found that similarly to European countries, patterns in wealth inequality (stock data) differ strongly from patterns of income inequality. Wealth is more unequal distributed than income: the Lorenz curve for net worth is further away from the 45 degree line and its Gini coefficient is larger ( 0.573 versus 0.422 ). The median to mean ratio is 0.56 and 0.80 for net worth and income, respectively. Net worth of the 25 th percentile was about $40 \%$ of the median, while the net worth of the 90 th percentile was 4.3 times that of the median wealth. The corresponding findings for the income are $50 \%$ and 2.5 times, respectively. The relative share of the highest decile of the population is closed to $40 \%$ of total net worth, $65 \%$ of total financial wealth and to $28 \%$ of total income. The transition matrix shows that about $34 \%$ of the families are ranked in the same quintile according to net worth and income, about $35 \%$ of families are ranked higher by net worth than by income and $31 \%$ were ranked higher by income than net worth (found below the diagonal of the transitions matrix).
\end{abstract}

Keywords: Inequality, wealth, net worth, income, SHARE - Israel.

\section{Keywords:}

Inequality, wealth, net worth, income, SHARE - Israel. 